\title{
Research on the Construction of Credit Risk Evaluation System of Foreign Trade Customers for a Foreign Trade Food Company
}

\author{
Wei Guo ${ }^{1}$, Haicheng Zhang ${ }^{2}$, and Yingjie Song ${ }^{3}$ \\ ${ }^{1)}$ Dongbei University, Qinhuangdao Institute of Technology, Qinhuangdao, Hebei, China \\ ${ }^{2)}$ Qinhuangdao Institute of Technology, Qinhuangdao, Hebei, China \\ ${ }^{3)}$ Qinhuangdao City Planning Bureau, Qinhuangdao, Hebei, China
}

\begin{abstract}
The research object of this document is the construction of credit risk evaluation system of a domestic foreign trade food processing enterprises. Through the establishment of foreign customer credit risk evaluation system, it makes the enterprise develop accurate strategy with foreign trade customers, limit credit quota, credit method of payment, deadline and establish information management system and the database according to the customer resources, which realizes the informationization and modernization of the management of the foreign customer credit risk assessment, in order to replace the extensive management mode which includes heavy human factors. In addition, this document analyses the possible foreign customer credit risk, the possible impact caused by the risk and warning processing method. In the case of accuracy of the early warning information, we should simplify risk assessment, clear the division of responsibilities, assessment process and assessment standard of the internal credit risk assessment, and puts forward some advice of the credit risk evaluation, in order to make the selection of foreign customers more accurately and quickly and avoid all kinds of foreign trade credit risks.
\end{abstract}

Keywords - foreign trade customers, credit risk evaluation, construction

\section{基于对某外贸食品公司外贸客户信用风险评估体系构 建的研究}

\author{
郭巍 $^{1} \quad$ 张海成 $^{2}$ 宋英杰 $^{3}$ \\ 1) 东北大学，秦皇岛职业技术学院，秦皇岛，河北，中国 \\ 2) 秦皇岛职业技术学院, 秦皇岛, 河北, 中国 \\ 3）秦皇岛市规划局海港分局，秦皇岛，河北，中国
}

摘 要 本文以国内某外贸食品加工企业的信用风险评价体系的构建为研究对象, 通过建立外贸客户信用风险评估体系, 使企业 准确制定与国外贸易客户的交易策略, 限定㻌账限额、㻌账付款方式、期限, 并根据客户资源建立信息管理系统和数据库, 使外贸客 户信用风险评估管理实现信息化、现代化, 以替代目前人为因素较重的粗放式管理方式。此外, 对外贸客户可能出现的信用风险、风 险可能造成的影响以及预警处理方法进行分析研究，在保持预警信息准确的情况下，简化风险评估工作量，明确企业内部的信用风险 评估责任分工、评估流程、评估标准，并向企业提出外贸客户信用风险评估的建议，从而使企业更加准确、快捷的选择外贸客户，避 免各类外贸信用风险发生。

关键词＼cjkstart外贸客户，信用风险评价，构建

1. 引言

企业信用风险管理已成为我国经济理论研究中的新领
域, 越发引起人们的重视。作为信用风险管理的一个重要 环节, 信用风险评估对于企业合理授信、控制客户信用风 
险具有非常重要的作用, 值得我们去深入研究。而对于外 贸企业来说, 构建符合企业自身特点的信用风险评价体系 显得尤为重要。

\section{2. 某外贸食品公司外贸客户信用风险评估体系研究}

\section{1 外贸客户信用风险评价指标}

为更加准确掌握外贸客户信用情况, 按照静态和动态 的分类制定某外贸客户信用风险评估体系。静态定量指标 主要考虑企业的财务效益状况、资产运营状况。这里包括 定量考核指标和定性考核指标。定量考核指标主要体现在 财务状况和资产运营状况两个方面, 主要有净资产收益率、 总资产报价率、成本费用利用率、总资产周转率、流动资 产周转率、财产损失比率。定性考核指标主要考虑企业外 部因素和企业自身因素两方面, 主要有国家风险、行业地 位、市场规模、公司管理制度、管理人员稳定度及开拓市 场能力。动态定量指标主要考虑企业的履约能力和交易能 力。主要包括贷款逾期率、应付货款清付率、毁约率、交 易金额、利润率、交易增长趋势率。动态定性指标主要考 虑企业的支付能力和履约保障能力。主要包括支付方式、 付款时间、支付银行信用、合同规范性、担保方式、合作 关系。

对外贸客户静态因素的分析, 是在企业与客户签订贸 易合同之前, 从不同角度对客户的经营状况进行观察, 分 析判断出外贸客户的信用风险等级。对外贸客户的动态因 素分析, 则更多的是关注企业与外贸客户交易过程中可能 发生的风险, 这些风险一般会通过履约能力变化、交易能 力变化、货款支付能力变化等表现出来, 判断外贸客户的 动态信用等级。

\section{2 专家评分系统}

通过参考专业评级机构的评分标准, 同时征求 30 位专 家评审意见拟定专家评分标准, 从一个侧面可以反映外贸 客户的信用情况。具体静态定性指标评分标准如表 1 。

外贸客户的基本状况是企业关心的主要内容, 这很可 能决定着此单交易能否如约进行。如果外贸客户的经营状 况令人担忧, 直接反映出与该客户交易的风险较大, 企业 在对外贸易中则会选择规避风险或采取预防措施。因此客 户的经营状况是给企业的第一印象, 十分重要。判断外贸 客户经营状况, 主要通过其行业地位、市场规模、公司管 理制度、管理人员稳定程度及开拓市场能力来评估判断。

外贸客户内部的稳定程度对贸易影响很大, 如果客户 在这些方面都能处于优势状况, 企业对整个外贸交易无疑 更有信心，可能出现的风险就更小。
外贸客户的动态定性分析是外贸客户信用风险评估的 重要监管环节, 也是信用风险评估体系中最复杂的环节。 如表 2 。

客户的动态经营状况主要考察客户的还款能力, 在这 六个方面能力强的客户, 说明其经营状况较好, 拖欠货款 的风险较低。客户的经营状况是一个变量, 经常会随市场 变化改变, 因此客户经营状况需要适时观察, 及时反馈, 做好监控。

\section{3 加权平方和法的信用评估}

加权平方和法是目前经济评价中应用最多的一种方 法。一般做法是根据各具体指标在评价总目标中的不同地 位, 给出或设定其标准权数; 同时确定各具体指标的标准 值 (通常为平均值)。然后比较指标的实际数值与标准值, 得到级别指标分值, 最后汇总指标分值求得加权评估总分。

评价矩阵建立。在深入分析该公司外贸评估问题后, 将问题中所包含的因素划分为不同的层次, 最后一层是进 行评价的 $\mathrm{n}$ 个具体指标, 这些具体指标值构成对信用评估 的评价矩阵

\section{$E i j(1 \leq j \leq n, i=1)$}

判断矩阵的标准化。一般而言, 指标体系中均有不同 程度的量纲, 需要将不同量纲的评价指标, 通过适当的变 换 (如向量归一化、线性比例变换、极差变换等方法) 化 为无量纲的标准化指标, 使评价指标标准化。

确定评价问题的理想点。

$$
V^{*}=\left\{V_{l}^{*}, V_{2}^{*}, \ldots, V_{n}^{*}\right\}
$$

其中: $\mathrm{Vj}^{*}=\max \{\mathrm{Yij}\} \quad(1 \leq \mathrm{j} \leq \mathrm{n})$

计算评价指标的权重向量 $\mathrm{W}=(\mathrm{W} 1, \mathrm{~W} 2, \ldots, \mathrm{Wn})$

令加权标准化矩阵为: $Z=(Z i j) 1 \times n=(W j Y i j) 1 \times n$

取各方案到理想点的距离平方, 即加权平方和值为评 判的依据。根据

$$
d_{i}=\sum\left(Z_{i j}-W_{j} V_{j}^{*}\right)^{2}=\sum\left(Y_{i j}-V_{j}^{*}\right)^{2} W_{j}^{2}(1 \leq j \leq n)
$$

做拉格朗日函数

$$
\begin{gathered}
L=\sum \sum\left(Y_{i j}-V_{j}^{*}\right)^{2} W_{j}^{2}+\lambda\left(\sum W_{j}-1\right), \text { 令 } \\
\frac{\partial L}{\partial W_{j}}=0, \frac{\partial L}{\partial \lambda}=0
\end{gathered}
$$




$$
\begin{aligned}
& W j=\frac{1}{\left[\sum \frac{1}{\sum\left(_{i j} V_{j}^{*}\right)^{2}}\right]\left[\sum\left(Y_{i j}-V_{j}^{*}\right)^{2}\right]}, \quad \lambda=-\frac{1}{2 \sum \frac{1}{\sum\left(\mathrm{Y}_{i j}-V_{j}^{*}\right)^{2}}} \\
& (1 \leq j \leq n) \ldots . .(1)
\end{aligned}
$$

\begin{tabular}{|c|c|c|c|c|c|}
\hline 项次 & 评价内容 & & 评价标准 & 分值 & 得分 \\
\hline \multirow{5}{*}{1.1 国家风险 } & \multirow{5}{*}{ 风险级别 } & 优 & A 类国家 & 10 & \\
\hline & & 良 & B 类国家 & 8 & \\
\hline & & 可 & $\mathrm{C}$ 类国家 & 6 & \\
\hline & & 差 & $\mathrm{D}$ 类国家 & 3 & \\
\hline & & 很差 & $\mathrm{E}$ 类国家 & 1 & \\
\hline \multirow{3}{*}{2.1} & \multirow{3}{*}{ 行业地位 } & 优 & 国际知名市场份额 10\%以上 & $6-10$ & \\
\hline & & 良 & 区域知名市场份额 5\%-10\% & $3-5$ & \\
\hline & & 差 & 市场份额 5\%以下 & $1-2$ & \\
\hline \multirow{3}{*}{2.2} & \multirow{3}{*}{ 市场规模 } & 优 & $\begin{array}{c}200 \text { 人以上年销售 } 4000 \text { 万美元 } \\
\text { 以上 }\end{array}$ & $8-10$ & \\
\hline & & 良 & $\begin{array}{l}\text { 100-200 人年销售 4000-1000 } \\
\text { 万美元 } \\
\end{array}$ & $4-7$ & \\
\hline & & 差 & $\begin{array}{c}100 \text { 人以下, 年销售 } 1000 \text { 万美 } \\
\text { 元以下 }\end{array}$ & $0-3$ & \\
\hline \multirow{3}{*}{2.3} & \multirow{3}{*}{$\begin{array}{c}\text { 公司管理 } \\
\text { 制度 }\end{array}$} & 优 & 制度健全管理严格 & $8-10$ & \\
\hline & & 良 & 有制度不完善 & $5-7$ & \\
\hline & & 差 & 无制度管理混乱 & $0-4$ & \\
\hline \multirow{3}{*}{2.4} & \multirow{3}{*}{ 管理人员稳定度 } & 优 & 5 年未更换业务能力强 & $7-10$ & \\
\hline & & 良 & 3 年未更换业务能力一般 & $4-6$ & \\
\hline & & 差 & 1 年内更换频繁 & $0-3$ & \\
\hline \multirow{3}{*}{2.5} & \multirow{3}{*}{$\begin{array}{l}\text { 开拓市场 } \\
\text { 能力 }\end{array}$} & 优 & 能力强 & $8-10$ & \\
\hline & & 良 & 能力一般 & $4-7$ & \\
\hline & & 差 & 能力差 & $0-3$ & \\
\hline
\end{tabular}

表 1 静态定性指标评分标准 
表 2 动态定性指标评分标准

\begin{tabular}{|c|c|c|c|c|c|}
\hline 项次 & 评价内容 & & 评价标准 & 分值 & 得分 \\
\hline \multirow{3}{*}{3.1} & \multirow{3}{*}{ 支付方式 } & 优 & 预付款 & $7-10$ & \\
\hline & & 良 & 分期预付款 & $3-6$ & \\
\hline & & 差 & 㻌销 & $0-2$ & \\
\hline & & & & & \\
\hline \multirow{3}{*}{3.2} & \multirow{3}{*}{ 付款时间 } & 优 & 交易前 & $8-10$ & \\
\hline & & 良 & 交易过程中 & $4-7$ & \\
\hline & & 差 & 交易结束后 & $0-3$ & \\
\hline & & & & & \\
\hline \multirow{3}{*}{3.3} & \multirow{3}{*}{ 支付银行信用 } & 优 & 信誉好, 长期合作 & $7-10$ & \\
\hline & & 良 & 信誉一般, 偶尔合作 & $3-6$ & \\
\hline & & 差 & 信誉差, 发生过信用风险问题 & $0-2$ & \\
\hline & & & & & \\
\hline \multirow{3}{*}{3.4} & \multirow{3}{*}{ 合同规范性 } & 优 & 本企业制式合同 & $8-10$ & \\
\hline & & 良 & 协商合同 & $4-7$ & \\
\hline & & 差 & 临时合约 & $0-3$ & \\
\hline & & & & & \\
\hline \multirow{3}{*}{3.5} & \multirow{3}{*}{ 担保方式 } & 优 & 直接预付款 & $8-10$ & \\
\hline & & 良 & 固定资产担保 & $4-7$ & \\
\hline & & 差 & 无担保 & $0-3$ & \\
\hline & & & & & \\
\hline \multirow{3}{*}{3.6} & \multirow{3}{*}{ 合作关系 } & 优 & 合作三年以上 & $7-10$ & \\
\hline & & 良 & 合作一年以上 & $3-6$ & \\
\hline & & 差 & 第一次合作 & $0-2$ & \\
\hline
\end{tabular}

计算各方案的综合评价值。

$$
d_{i}=\sum\left(Y_{i j}-V_{j}^{*}\right)^{2} W_{j}^{2}(1 \leq j \leq n)
$$

根据综合评价值，对各方案进行排序。

根据上面加权平方和法的应用步骤, 对于定量指标选 择极差变换算法来标准化, 定性指标可采取专家打分法, 最后将分数整合, 可以建立外贸客户静态信用风险评估模 型。此外，建立外贸客户动态信用风险评估模型。

利用建立的静态和动态信用评估模型, 对与该公司开 展贸易活动的外贸客户进行信用风险评估, 不仅关注外贸 客户在签订合同时的信用等级, 而且时刻监控外贸客户在 履行合同期间的风险因素。参考国内外信用评级机构评价 标准, 结合该公司实际情况, 从而确定客户的信用等级范 围, 为企业对外贸客户采取何种风险防范措施提供可靠依 据。

\section{3. 小结}

通过以上对某外贸食品公司外贸客户信用风险评估体 系研究, 主要阐述了影响外贸活动的静态信用指标和动态
信用指标，提出建立信用评估模型、专家评价系统，再通 过加权平方和法实现对金海食品公司的外贸客户进行信用 风险评估, 评估结果按等级划分, 规范客户风险评估工作 程序, 最终的客户信用等级可为企业决策提供可靠依据。

\section{参考文献(References)}

[1] Jianmin Pang, "Research on credit management of enterprise -Based on the analysis of the case," Financial research, 2007.

[2] Beiyang Zhang, "Listing Corporation credit risk, corporate governance and corporate performance in association studies," Jilin University, 2011.

[3] Yaqing Wen, "Independent matrix type of credit management model design of Economic Research Journal," Economic Research Guide, 2006.

[4] Xiangkui Li, "Research on the operation mechanism of enterprise credit system in China, "Jilin University, 2006

[5] Lihui Xia, "Problems and Countermeasures of enterprise credit management, "Chinese total accountant excellent papers(2008), 2009 